\title{
Eunice sebastiani SP. NOV. (ANNELIDA, POLYCHAETA)
}

(Recebido em 17/5/1965)

\author{
E. Nonato \\ Instituto Oceanográfico da Universidade de São Paulo
}

\section{SYNOPSIS}

Eunice sebastiani, a new species here described, belongs to the group of species called "fuscus-bidentate" by Hartman, and which includes E. aphroditois Pallas.

Like some of the others which belong to the same genus, it grows to a great size. It lives in almost vertical galleries, in muddy beaches, generally in the intertidal zone.

It resembles E. aphroditois Pallas (as in a figure by Izuka 1912) and $E$. roussaei Quat. in its size, and external characteristics.

E. sebastiani can be distinguished from the species mentioned chiefly by the different form of the mouth parts and dorsal cirri of the anterior and median feet.

The mouth parts (Fig. 2) are light grey in colour; the maxilla I ("forceps") has thin and almost cylindrical branches; maxilla II is narrow and has very long teeth.

Length of one specimen with 450 segments: $208 \mathrm{~cm}$; width in the anterior region $2 \mathrm{~cm}$; length of gills: $1.6 \mathrm{~cm}$.

Colour varying from flesh-colour to dark brown, iridescent.

\section{INTRODUÇÃO}

Eunice sebastiani sp. nov., aqui descrita, foi encontrada pela primeira vez em praias próximas a São Sebastião, no litoral norte do Estado de São Paulo e inclui-se entre os maiores representantes da família Eunicidae.

A descrição é baseada no estudo de 10 exemplares de tamánhos diversos, tendo sido escolhido como tipo um dos espécimes maiores e completo, proveniente da Praia do Araçá, em São Sebastião.

DiAgNose - Eunicidae de grande porte, do grupo "fuscus bidentate" de Hartman (1944). Peças bucais de côr clara, amarelo

Publ. n॰221 do Inst. Ocean. da USP. 
a cinza-esbranquiçado; maxila ("forceps") longa e delgada; maxila II estreita, com 4-5 dentes longos e agudos. Cirros dorsais dos pés da região anterior, com forma peculiar, dotados de um "calcanhar" conspícuo.

TIPo - Espécime adulto. Depositado no Museu do Departamento de Zoologia da Secretaria da Agricultura.

DESCRIÇÃo - Corpo vermiforme, robusto, com segmentos muito numerosos; a região anterior é de secção aproximadamente cilíndrica; a região mediana e posterior achatada, de secção elíptica. Prostômio maciço, com antenas curtas, lisas e aneladas de negro ou com artículos apenas indicados; olhos pequenos, inconspícuos. Cirros tentaculares muito mais curtos que o segmento bucal, subulados ou piriformes acuminados (triangulares). Pigmentação variável com a procedência e a idade, porém homogênea ao longo do corpo. Sob a lupa, são perceptíveis pequenas manchas punctiformes, areoladas, de côr clara, sôbre fundo róseo-carne ou cinzento até prêto-azulado; cutícula iridescente. Brânquias rubras.

Pés anteriores providos de cirros dorsais e ventrais bem desenvolvidos; nos subseqüentes os cirros dorsais tornam-se mais curtos e largos, com uma expansão basal em forma de calcanhar e os ventrais se reduzem a pequenos mamelóes (Fig. 3). A região mediana do pé é constituída por um curto tubo de secção elíptica, com uma "crista" vertical ao longo do maior diâmetro. Nesta crista, entre ela e a parte posterior do pé, situam-se, dorsalmente, as cerdas pectinadas e, ventralmente, as aciculares. $\mathrm{O}$ cirro dorsal é sustentado por um feixe de acículos delgados, profundamente inclusos.

Brânquias aparecem a partir do $7 .^{\circ}$ setígero; a primeira ou as duas primeiras, simples; as seguintes pectiniformes, com número crescente de ramos. Na região mediana (setígeros $100^{\circ}$ a $300^{\circ}$ ) as brânquias atingem seu desenvolvimento máximo, com cêrca de 30 filamentos e comprimento igual ao diâmetro do segmento.

Cerdas, tôdas com hastes de côr escura até negra e extremidades ou artículos claros. Acículos totalmente negros, inclusive os que estão inclusos no cirro dorsal. As cerdas pectinadas constituem um feixe denso, na parte dorsal do pé; possuem 10 a 12 "dentes", com os externos mais longos e a parte espatulada recoberta por escamas muito mais finas. As cerdas limbadas são as mais numerosas (cêrca de 30-40 num pé mediano) e ocupam posição intermediária, reunidas num feixe alongado. As cerdas compostas estão agrupadas na parte ventral do pé, formando feixes de ambos os lados e abaixo dos acículos. Têm conformação característica, com a extremidade da haste muito dilatada e o artículo terminando por uma ponta bidentada, inclusa entre duas lâminas transparentes. Êsse aspecto é perfeitamente conspícuo, em vista 
frontal. As cerdas aciculares aparecem, em número de uma ou duas por pé, a partir dos primeiros segmentos branquiais. Assemelham-se aos acículos, dos quais se distinguem apenas pela posição, que é ventral e fora da crista onde êstes são inseridos. Nas cerdas novas é perceptível uma ponta ligeiramente recurvada e translúcida.

Maxilas de côr clara, cinzenta ou amarelo-esbranquiçada. Maxila I ("forceps") longa e robusta; maxila II, estreita com 5 a 7 dentes longos e bem conformados, de forma peculiar e 1 a 3 , basais, pouco desenvolvidos; maxila III (ímpar) estreita, retangular e recurvada, com 5 a 7 dentes, em serra; maxila IV, estreita, recurvada, com 8-10 dentes à direita e 5 a 6 à esquerda; maxila $\mathrm{V}$, constituída por peças pequenas, com 1 ou 2 dentes. Uma pequena peça acessória, lenticular e bem calcificada foi encontrada em alguns exemplares.

Mandíbulas de côr negra, com bordo cortante, incrustado de calcário branco translúcido.

Discussão - Eunice sebastiani pertence ao grupo de espécies que inclui $E$. aphroditois Pallas e que Hartman denominou "fuscus bidentate".

Como algumas de suas congêneres, atinge grande tamanho e habita galerias quase verticais, em praias de areia lodosa, geralmente nos limites da zona das marés.

Pelo tamanho e características externas, assemelha-se a $E$. aphroditois Pallas e a $E$. roussaei Quatrefages. Distingue-se destas, principalmente, pela conformação diversa das peças maxilares (Fig. 2). Outros caracteres, como a côr, posição da primeira brânquia ou número máximo de filamentos branquiais não são suficientemente constantes para constituir critério válido. As peças bucais de $E$. sebastiani são tão peculiares que constituem, a nosso ver, elementos decisivos para a sua distinção. A côr, quase branca, das maxilas é rara, senão única. O "forceps", com ramos delgados, de secção aproximadamente cilíndrica e a maxila II, dotada de dentes muito longos, diferem nitidamente dos encontrados na maioria das espécies de Eunice.

Quanto às cerdas, é indubitável a semelhança entre as de $E$. sebastiani e as de E. roussaei figuradas por Fauvel (1917, p. 222, fig. XIX). Entretanto, são também caráter de valor duvidoso. Cremos que assim as considerou o autor ao concluir, em 1932 (p. 134), que "não há razão para considerar as duas formas como espécies distintas".

Para melhor fundamentar a decisão de descrever como nova a espécie atual e distinguí-la das anteriormente conhecidas, consideramos oportuno precisar o nosso ponto de vista sôbre a suposta identidade de $E$. roussaei e $E$. aphroditois. A nosso ver, não há nenhum sentido em considerar a grande Eunice, figurada por Quatrefages, idêntica à espécie de Pallas. 
Apesar da análise pormenorizada feita por Fauvel (1919; 1932) e por Pruvot (1930), nenhuma conclusão convincente foi obtida. É cômodo e aceitável admitir, com Pruvot (loc. cit., p. 67) que, em lugar de duas espécies "rigorosamente distintas", tratarse-ia, realmente, de uma única espécie que se modifica, à medida que se progride de oeste para leste. A área de distribuição de roussaei estender-se-ia do Mediterrâneo até a África austral e a de aphroditois compreenderia o Oceano índico e o Pacífico. Entretanto, impõe-se distinguir a forma Indo-Pacífica da Atlântica, e o próprio Pruvot o reconhece, ao sugerir que sejam consideradas subespécies e propondo as designações $E$. aphroditois genuina e $E$. aphroditois roussaei. Ainda assim, como tal similitude entre boas espécies, não é apanágio do gênero Eunice, o mais sensato será mantê-las como espécies diferentes.

Menos razoável é atribuir à esplêndida Eunice, figurada por Quatrefages, o nome de aphroditois.

É surpreendente que, em sinonímia tão controvertida ("with regard to the synonymy of $E$. aphroditois there has been endless discussion", Fauvel 1932, p. 133), não se haja dado maior atenção a caracteres importantes como a forma das peças bucais e as características dos pés.

As únicas ilustrações recentes e satisfatórias que pudemos encontrar foram as de Izuka (1912). A fotografia da região anterior de $E$. apłhroditois (pl. 2, fig. 2) é perfeitamente comparável a de um dos nossos exemplares. Antenas e cirros tentaculares têm as mesmas proporções e o mesmo aspecto. Entretanto, os detalhes das maxilas e das cerdas são muito diferentes. $\mathrm{O}$ pé, figurado por Izuka $\left(64^{\circ}\right)$, difere do seu equivalente de E. sebastiani, pela forma do cirro dorsal, pela ausência de acículos dorsais e pelo número de cerdas aciculares. Êste último caráter tem valor limitado, pois a presença de tais cerdas, mesmo em sebastiani, não é regular. Por outro lado, o tipo de cerda não pectinada (fig. 5) é muito peculiar, completamente diverso do encontrado na espécie atual.

A construção de um tubo como "a pretty thick tube in which the body was entirely concealed" observada por Izuka (loc. cit., p. 114) não é referida por nenhum outro autor. E. sebastiani não constrói um tubo verdadeiro, ainda que possa revestir de muco suas galerias ou aglutinar areia e detritos, em volta do corpo.

A propósito, é interessante constatar que a aptidão para construir um tubo ocorre em outras espécies de Eunice e, por vêzes, foi considerado critério para caracterizar uma variedade. É o caso de E. antennata var. aedificatrix, descrita por Monro (1933, p. 60) .

Quanto a Eriphyle capensis Kinberg (=Eunice kinbergi Ehlers), do Cabo da Boa Esperança, parece-nos ser, realmente, idêntica ao material de Izuka. Ainda que a descrição de Kinberg seja por demais sucinta, suas figuras são boas e permitem uma 


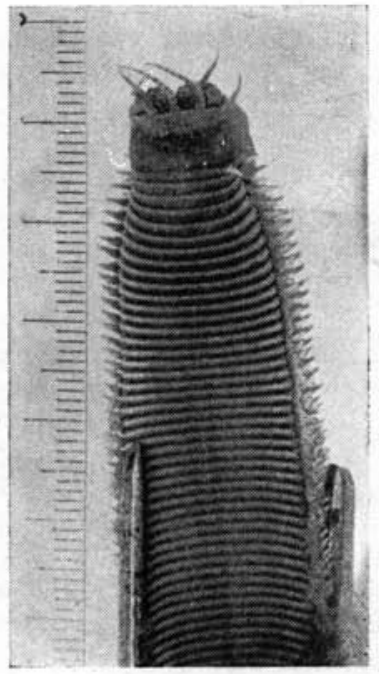

1

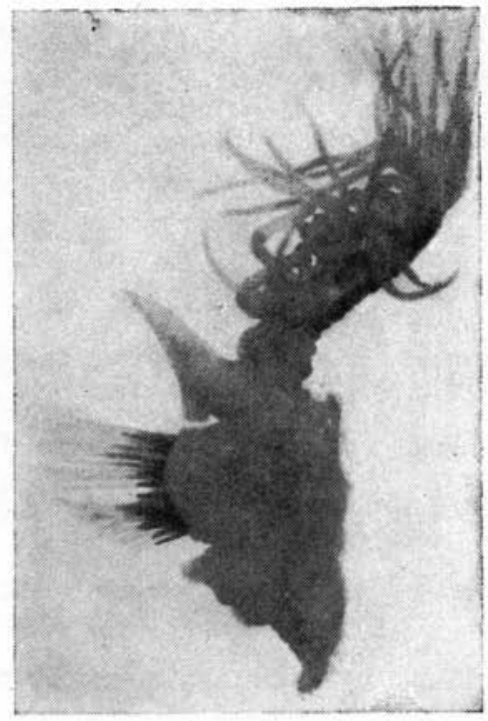

3

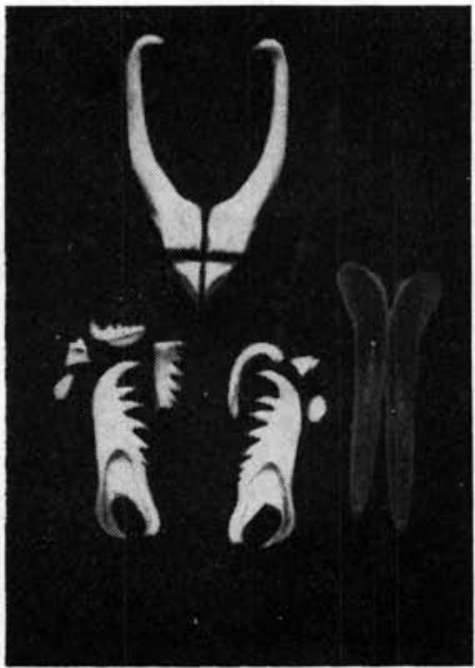

2
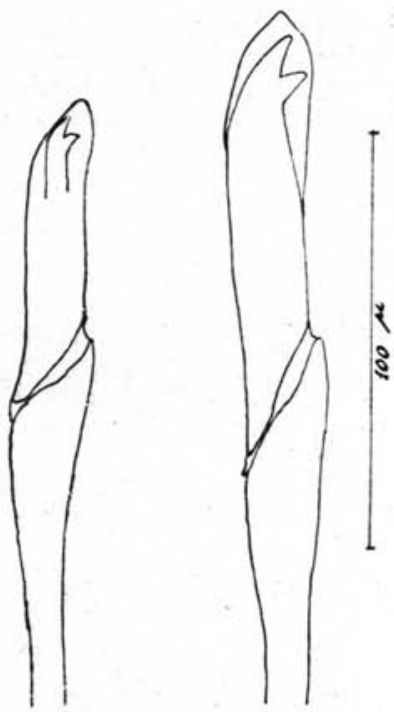

4

E. sebastiani sp. nov.

Fig. 1 - Região anterior, dorsal.

Fig. 2 - Peças bucais, desarticuladas.

Fig. 3 - Pé da região mediana.

Fig. 4 - Cerdas compostas, encapuzadas, de um pé anterior. 
apreciação satisfatória. As peças bucais e a forma do pé mediano (pl. 15 , figs. $16 \mathrm{~F}$ e $16 \mathrm{E}$ ) de $E$. capensis são perfeitamente comparáveis às de E. aphroditois do Japão.

MedidAs - O exemplar da Figura 1, um dos maiores capturados inteiros, com cêrca de 450 segmentos, media $208 \mathrm{~cm}$; o maior diâmetro, na parte anterior, alcançando $2 \mathrm{~cm}$ e as brânquias mais longas, $1,6 \mathrm{~cm}$.

OCORRÊNCIA - O exemplar-tipo foi colhido na praia do Araçá, São Sebastião; praia lodosa, com substrato rico em matéria orgânica. Nessa região a espécie é abundante, ocorrendo em associações onde predominam, como formas mais conspícuas, Balanoglossus gigas, Arenicola glasselli e Ammotrypane aulogaster.

$\mathrm{Na}$ região de Ubatuba a espécie é mais rara, ocorrendo tanto em praias lodosas, ao lado de Chaetopterus variopedatus, quanto em praias de areia relativamente limpa (praia da Enseada), juntamente com Arenicola brasiliensis e Ptychodera sp.

\section{R ES U M O}

É descrita uma espécie nova de Eunice gigante, encontrada pela primeira vez nas praias de São Sebastião, Estado de São Paulo. A espécie distingue-se das congêneres, pelas características das peças bucais e pela forma do cirro dorsal dos pés da região anterior. São também analisadas as afinidades com outras espécies. próximas, particularmente com E. aphroditois.

\section{B I B L I O G R A F I A}

EHLERS, E.

1864/68. Die Borstenwürmer nach systematischen und anatomischen Untersuchungen dargestellt. Leipzig, Wilhelm Engelmann. xx + 748 p., ests 1-24.

FAuvel, P.

1917. Annélides polychètes de l'Australie meridionale. Archs Zool. exp. gén. Paris, vol. 56, p. 159-278, 6 ests, 2 mapas.

1932. Annelida polychaeta of the Indian Museum. Calcutta. Mem. Indian Mus. Calcutta, vol. 12 , n. $^{\circ} 1$, p. $1-262,40$ figs, 9 ests.

1953. Annelida. Polychaeta. (The fauna of India, including Pakistan, Ceylon, Burma and Malaya). Allahabad Univ. Stud., xii + 507 p., 250 figs.

HARTMAN, O.

1944. Polychaetous Annelids, est. 5, Eunicea. Allan Hancock Pacif. Exped., vol. 10, n. ${ }^{\circ}$, p. 1-238, 18 ests.

IZUKA, A.

1912. The errantiate Polychaeta of Japan. J. Coll. Sci. imp. Univ. Tokyo, vol. 30 , art. 2, p. 1-262, 24 ests. 
KINBERG, J. G. H.

1858/1910. Konglia Svenska Fregatten EugenIEs Resa ombring jorden under befäl af C. A. Virgin aren 1851-1853. Zoologia. 3. Annulater. Uppsala \& Stockholm, Almquist \& Wicksells. 78 p., 29 ests. (Edição completa publicada em 1910).

Monro, C. C. A.

1933. The Polychaeta Errantia collected by Dr. C. Crossland at Colón in the Panamá region and the Galapagos Islands during the expedition of the S.Y. St. "George". Proc. zool. Soc, Lond., pt. 1, p. 1-96, 36 figs.

Pruvot, G.

1930. Annélides polychètes de Nouvelle-Caledonie recuillies par M. François. Archs Zool. expl. gén. Paris, vol. 70, p. 1-94, 8 figs, 3 ests.

Quatrefages, A.

1865/66. Histoire naturelle des Annélides marins et d'eau douce. Annélides et Gephyriens. Paris, Libr. Encycl. de Rôret, 3 vol. + 1 atlas.

SAINT-JosEPH, A.

1898. Les Annélides polychètes des côtes de France (Manche et Océan). Annls Sci. nat. Paris, sér. 8, vol. 5, p. 209-464, ests. 13-23. 